\title{
Introduction: Researching Workplaces as Learning Spaces
}

\author{
Karen Evans, Annette Ostendorf and Chompoonuh K. Permpoonwiwat
}

The Research Network on Workplace Learning (RN2) has directed its attention to the task of decoding working places in Asia and Europe as lifelong learning spaces. Workplaces encompass not just companies and public services, but also a wide range of organisational and social contexts, including non-profit-making NGOs and voluntary work, as well as diverse forms of self-employment, sometimes under irregular and precarious conditions. They offer very different kinds of learning opportunities: some are learning-conducive, others are less so; some provide structured work-related education and training for employees, whereas in others, learning is integrated into the flow of working processes. Learning spaces are constructed through the interplay of workplace structures and practices with formal, non-formal and informal learning. They provide a framework for understanding how opportunities for lifelong learning, including professional and personal development at work, are distributed, structured, experienced and used. Through exchange of information, workshop discussions and joint studies of how workplace learning is provided, practised and understood in Asian and European countries, RN2 is building up a shared body of knowledge that is empirically based, contextualised and theoretically informed.

RN2 was established in 2005 and meets at least once each year. Its members currently come from 15 countries. Its work has shown how not only frameworks of meanings but also socio-cultural and economic contexts vary considerably across the heterogeneous national contexts and organisational segments. The Network's activities, membership and reports are available for download at http://www.dpu.dk/asem/researchnetworks/workplacelearning/.

The 'Workplaces as Learning Spaces' inquiry was initiated in 2013, proceeding from the former work of RN2 (Chisholm et al. 2007, 2012). Early in 2015, RN2 played an active role in the ASEM LLL Hub Forum Renewing the Agenda for Lifelong Learning, held in Bali, Indonesia, sharing expertise and research insights with researchers, policy makers and practitioners in both seminar and plenary sessions. It also took the final steps towards the spring 2015 launch of the annotated 
bibliography Workplaces as Learning Spaces: Contextualising Lifelong Learning in Asia and Europe, coordinated by Elina Maslo and Katharina Lunardon, and announced the planned special issue (RN2_Annotated_Bibliography first_edition_08-10-2015.pdf) of the International Review of Education on 'Workplace Learning, Subjectivity and Identity', guest edited by Valérie CohenScali and Theo van Dellen (http://link.springer.com/journal/11159/61/6/page/1). At an international symposium hosted by Masaryk University in Brno, Czech Republic (November 2015), Annette Ostendorf and Elina Maslo led a Methodology Workshop on 'Decoding visual materials in the context of participatory photo interviews in ASEM research projects', sharing aspects of the working methods used in the research with a wider audience. At a second international symposium held in Glasgow, Scotland (June 2016), the publication plans for this volume were finalised.

Through our experiences of carrying out these empirically based and theoretically informed studies, we have been increasingly cognisant of the scale of the challenges faced by comparative research on workplace learning between Asia and Europe. How spaces for learning are understood differs considerably between the countries represented in the Network, or rather, between the societies and cultures these countries represent. Some of these differences may turn out to belong to the defining features of 'Asian', as opposed to 'European', civilisations and their contemporary economic and political structures. Others reflect variations in cultural, economic, political and social features within Europe and within Asia. Accounting for these undoubtedly complex patterns is a matter of ongoing debate in the ASEM Lifelong Learning Hub.

Four guiding commitments continue to shape the Network's approach to developing its activities, building on Chisholm et al. (2012). Firstly, empirical research remains the only way to interrogate and rethink underlying assumptions about patterns of differences and similarities between Europe and Asia. Secondly, the collaborative nature of the research ensures that different perspectives have initially equal claims to legitimacy and are open to interrogation from potentially divergent standpoints. Thirdly, the representation of variety takes priority over demands for consistency and coherence. Finally, the Network currently favours methodological pluralism.

Workplace learning is profoundly interconnected with lifelong learning, the overarching theme of the ASEM Education and Research Hub, of which RN2 is part. Competing visions and paradigms for lifelong learning co-exist at national and international levels. The fact that one 'official' discourse may be dominant at any one time does not mean that other ways of thinking about lifelong learning have disappeared. They are alive and well in a range of critical traditions and perspectives that retain their power to engage and persuade. Network contributors critically 
analyse issues in lifelong learning and workplace learning that have important implications for policy in different parts of the world. Evidence, ideas and the polity can mobilise political thinking in new directions as policy makers search for the next 'big idea'. In turbulent times, ideas for ways in which system worlds and life worlds can become better connected can focus compellingly on learning as a lifelong process that links, rather than separates, the older and younger generations and incorporates the realities of working lives. This volume aims to incorporate the actualities of working lives in contrasting societal contexts in this debate.

The paper collection encompasses nine research contributions of RN2 members. Some arose as single papers, some as joint projects, some across different cultural backgrounds, some deepening the understanding of workplace learning in specific cultural contexts. Most of them have in common the use of qualitative empirical data for theorising and many of them include visual material as a source of research. This is the result of the RN2 methodological discussions from recent years at Network meetings, which have brought up interesting but not unquestioned suggestions for alternative ways of conducting qualitative research using visual methods, such as participatory photo interview. In this respect, this collection may be seminal for further discussions on progress in qualitative research methodology.

Natasha Kersh and Karen Evans start with a piece of research conducted to throw light on the processes and conditions fostering individuals' construction of their own learning spaces related to work. The authors used the photo-participatory method in a UK context of IT-related and university workplaces. With their article, they also prepare the theoretical ground for conceptualising workplaces as learning spaces, which is also important for the reading of the subsequent articles. Using workplaces as learning spaces is characterised as a complex phenomenon in a relational arrangement between work, learning, human agency and space.

Katharina Lunardon, Pier Paolo Pasqualoni and Chompoonuh K. Permpoonwiwat inverstigate transnational and transdisciplinary research networks as learning spaces. Tuckman's group development model leads their theoretical argumentation, inspired also by their own considerable experience. In addition, 'non-places' (such as hotels and train stations) are explained as a feature of learning spaces.

Theo van Dellen and Döndü Yurtmaz use participative photograph interviews and dynamic concept analysis to explain the workplace learning of adult learning professionals (such as teachers, trainers, coaches and counsellors). The focus is on the features of workplaces that restrict or foster learning and professional development. It is reported that, from the learners' perspective, learning 'just happens' in the workplace but obviously there is a demand for awareness of personal development in workplaces. It is astonishing that even adult learning professionals are not very reflective in this respect. 
Padma Ramsamy-Prat describes in her article the 'art' of workplace learning. Using two cases of young professionals working in an academic context, she is also able to explain the hidden dimensions of workplace learning that are strongly bound to creativity, intelligence and art. Micro-phenomenological interviewing, combined with the auto-photography method, was used to gain empirical evidence.

Elina Maslo investigates different perceptions of learning by interviewing two persons at the same workplace using the participatory photo interview method. With this design, she is able to explain individual perceptions of the learning potential of workplaces. Using categories of spatial analysis, a hybrid space is identified, transforming working and life aspects.

Daiva Bukantaite reports the findings of her research conducted with university administrators from eight universities in Lithuania. Using participatory photo interviews, she reveals that university administrators strongly relate their thinking about learning experience to the task performance process. The interpretation of learning is linked to the accomplishment of the given tasks. Trusting and encouraging them can be seen as important push factors for their learning.

Helen Bound and Arthur Chia use two semi-ethnographic cases from a research project on 'Assessment for the changing nature of work' conducted in Singapore to explain how and in what ways learning spaces mediate learning and assessment. They particularly focus on material (such as tools) and immaterial (such as discourses) practices and relational aspects within the learning space and give an alternative view of assessment issues.

Annette Ostendorf presents some empirical insights derived from an Austrian research project (PEARL) on learning at workplaces in business internships. One specific focus is on the 'opening phenomenon', which seems to be very important for the use of the 'learning space business internship'. The theorising is based on qualitative empirical data gained in a very specific way involving interns as 'junior researchers'

The contribution of Areeya Rojvithee gives insights into a strategy for increasing the productivity of labour in Thai workplaces. It is conceptualised as a policy report explaining the relationship between workplace training and productivity. In particular, SMEs are going to be encouraged to use the outcomes of the explained public-private partnership project.

We want to thank the ASEM LLL Hub for the financial grant for this paper collection and Eva Adelsberger-Höss for her help concerning the formatting process. 


\section{References}

Chisholm, L., Fennes, H. \& Spannring, R. (Eds.) (2007). Competence development as workplace learning. Innsbruck: Innsbruck University Press.

Chisholm, L., Lunardon, K., Ostendorf, A. \& Pasqualoni (Eds.) (2012): Decoding the meanings of learning at work in Asia and Europe. Innsbruck: Innsbruck University Press. 